\title{
Annotating Narrative Levels: Review of Guideline No. 7
}

\author{
Gunther Martens
}

01.15 .20

Article DOI: $10.22148 / 001 c .11775$

Journal ISSN: 2371-4549

Cite: Gunther Martens, “Annotating Narrative Levels: Review of Guideline No. 7," Journal of Cultural Analytics. January 15, 2020. doi: 10.22148/001c.11775

The guideline under review builds on the acquired knowledge of the field of narrative theory. Its main references are to classical structuralist narratology, both in terms of definitions (Todorov, Genette, Dolezel) and by way of its guiding principles, which strive for simplicity, hierarchy, minimal interpretation and a strict focus on the annotation of text-intrinsic, linguistic aspects of narrative. Most recent attempts to do "computational narratology" have been similarly "structuralist" in outlook, albeit with a stronger focus on aspects of story grammar: the basis constituents of the story are to some extent hard-coded into the language of any story, and are thus more easily formalized. The present guideline goes well beyond this restriction to story grammar. In fact, the guideline promises to tackle aspects of narrative transmission from the highest level (author) to the lowest (character), but also demarcation of scenes at the level of plot, as well as focalisation. Thus, the guideline can be said to be very wide in scope.

The shared task to which this guideline responds focuses on identifying and reaching consensus on the demarcation of narrative levels. In standard narratological parlance, shifts in level correlate to shifts in the information distribution from one narrative agent to another. In keeping with film terminology, these acts, including of the act of taking charge of the narration itself, are taken to be acts of framing constitutive of distinctive levels: "We will define this difference in level by saying that any event a narrative recounts is at a diegetic level immediately higher than the level at which the narrating act producing 
this narrative is placed." ${ }^{\prime}$ In Genette's view, narrative levels lead to an intricate nesting or embedding effect of speakers and viewers.

While the more comprehensive approach of the guideline will be more palatable to scholars trained in literary theory, it is to some extent undecided as to what it takes "levels" to mean. Though the guideline addresses a broad set of narrative features, it is ultimately geared towards annotating the most conspicuous shifts in narrative levels: the turn-taking in dialogues between characters and switches in voice from narrator to character and vice versa. This is certainly the part of the guideline most easily to be operationalized. It should be pointed out that the guideline chose to restrict its interaction with the shared task corpus to a minimum: only three of the texts are briefly cited, and the bulk of the examples stems from Sally Rooney's novel Conversations with friends. It is stated that: "The main components of such narratives are dialogues", which may help to explain why the annotation schema is more focused on reported speech than on reported thought.

While the current guideline takes its cue mainly from the tried-and-trusted toolkit of (textual) narrative theory, it is also informed by Digital Humanities. This can be seen when aspects of the paratext (Genette's short-hand notation for any extra-textual element that frames texts and guides their reception) are taken into account, for instance when the typographic make-up of chapters, paragraphs and quotation is considered as a machine-readable index of narrative levels. Likewise, aspects of the guideline go beyond structuralism when it undertakes to consider narratees and addressees. This extension of the narratological toolbox is in keeping with recent redefinitions of style in the area of Digital Humanities, as epitomized by the following definition:

In Digital Humanities, styler is seen as anything that can be measured in the linguistic form of a text, such as vocabulary, punctuation marks, sentence length, word length, the use of character strings. $^{2}$

The adoption of this line of reasoning becomes evident when the guideline draws on the layout of the texts: "alternations between discourse levels are usually signalled by paragraph breaks." It is certainly necessary and helpful to consider such material underpinnings of narrative structure. Yet, there is a wide variety in national and historical print cultures to be considered in this regard, so these apparently stable markers of narrative level should be handled with care and flexibility.

\footnotetext{
${ }^{1}$ Gérard Genette, Narrative Discourse: An Essay in Method (Ithaca: Cornell University Press, 1983), 228.

${ }^{2}$ J. Berenike Herrmann, Karina van Dalen-Oskam, and Christof Schöch, "Revisiting Style, a Key Concept in Literary Studies," Journal of Literary Theory 9, no. 1 (2015): 25-52.
} 
The guideline claims that it seeks to make the annotation amenable to machine learning so as to "predict narrative structure". While this is certainly a laudable ambition, it remains to be seen whether the guideline's heuristic focus actually allows for this. The current guideline is rather hybrid in nature. On the one hand, it caters to the hermeneutic strengths of human annotators. Especially the attempt to annotate the addressee(s) of specific utterances presupposes a lot of interpretation, as it hinges on implication and logical deduction rather than on actual mentions. Likewise, the guidelines for annotating focalisation strike me as undecided. The main reference here is Todorov, which is somewhat dated in view of the lengthy debates on various conceptualisations of focalisation and the question of its transferability to specific media. Focalisation is restricted to "perspective of the narrator". It would seem that even more semantics would be required to demarcate other types of focalisation. The ambition to cover these areas may run counter to the manual's declared adherence to structuralist tenets, as both rely on interpretation and semantics. Co-reference resolution of unstructured textual data (like fictional narratives) is notoriously difficult. ${ }^{3}$ Currently, automatic event detection on the basis of machine learning has proven most successful with regard to text genres that involve a lot of referential anchoring (e.g. news articles). ${ }^{4}$ The current state-of-the-art allows machine learning to predict structure "in the wild" only over a limited span of semi-structured text. ${ }^{5}$ Annotating the intricacies of implied audiences presupposes an even more extensive degree of co-reference resolution.

I would like to take issue with another specific decision: The guideline argues in favour of handling tags as cleanly as possible, in order to provide a visual analogy to levels that it demarcates. For instance, it encloses the markers that attribute discourse to specific characters within the tags that demarcate that very content. These attributive markers typically involve verba dicendi in the so-called inquitformulae. The main rationale for "includ[ing] the speech-verb construction in the line tag" is "to avoid cluttering the annotation". I am not convinced that this is a workable decision. This might seem to be an issue of lesser importance with regard to texts that keep this attributive marking to an absolute minimum, as is the case in the samples from the contemporary novel. Yet, if the focus of the shared task is indeed on identifying levels in a wide range of narrative texts, this decision is counterproductive. It undermines the attempt to identify levels and,

\footnotetext{
3"R/ProgrammerHumor - When Do We Want What?" reddit, accessed June 3, 2019.

${ }^{4}$ Tommaso Caselli and Oana Inel, "Crowdsourcing StoryLines: Harnessing the Crowd for Causal Relation Annotation," in Proceedings of the Workshop Events and Stories in the News 2018, 2018, 44-54.

${ }^{5}$ Markus Krug et al., "Rule-Based Coreference Resolution in German Historic Novels.," in CLfL@ NAACL-HLT, 2015, 98-104; S. Malec et al., "Landing Propp in Interaction Space: First Steps Toward Scalable Open Domain Narrative Analysis With Predication-Based Semantic Indexing," in DIVA, 2015.
} 
especially to extricate from sentences chunks that allow machines to identify patterns indicative of shifts in level. While the concatenation of discourse with discourse markers is in line with a fairly recent trend in postclassical narratology, as I discussed elsewhere, ${ }^{6}$ it would seem that these tags are kept to a minimum for the sake of human readability. Chunking at higher-order levels such as scenes is not necessarily the way to go when aiming for machine readability. In order to annotate narrative levels, it is mandatory to provide tagging at the micro-level of words rather than of sentences, paragraphs or even scenes. This will inevitably lead to a cluttered view to the human eye, but such a nesting of annotations is much more likely to lead to transfer learning. Much more meta-information is needed with regard to the framing verbs. These tags could then be linked with existing tag-sets that deliberately aim to target and/or attenuate contextual ambiguity, such as PropBank and FrameNet. Similar efforts are under way. A brief look at www.redewiedergabe.net might suffice to illustrate what such micro-coding may afford in terms of the detection of narrative levels. ${ }^{7}$

It is certainly laudable that the guidelines undertakes to emulate the structuralist annotation of complex aspects of narrative levels. It remains to be seen whether the textualist and bottom-up focus of this guideline warrants for a basis representative enough to provide a gold standard in order to extrapolate from. Granted, this is a dilemma that currently most attempts at doing computational narratology with roots in literary narrative theory are facing. While the adherence of the guideline to structuralist tenets can be lauded for its principled nature, there is much to be learned from the extension of the narratological toolkit in the direction of multimodality and paralinguistics. While references to time and coreference can be resolved with a high degree of confidence in formulaic genres like news articles or scientific articles, especially co-reference resolution in elliptic fictional texts like Virginia Woolf's can probably only be solved by looking at interactions of readers and other users with the text (e.g. through eye tracking ${ }^{8}$ or the study of adaption in other media ${ }^{9}$ ). Notwithstanding the many conceptual challenges of doing transmedia comparisons, one may profit from compar-

\footnotetext{
${ }^{6}$ Gunther Martens, "Narrative and Stylistic Agency: The Case of Overt Narration," in Point of View, Perspective, and Focalization. Modeling Mediation in Narrative, ed. Peter Hühn, Wolf Schmid, and Jörg Schönert, Narratologia (Berlin: De Gruyter, 2009), 99-118.

${ }^{7}$ Annelen Brunner et al., "Das Redewiedergabe-Korpus. Eine neue Ressource," in Digital Humanities: multimedial \& multimodal. 6. Tagung des Verbands Digital Humanities im deutschsprachigen Raum e.V. (DHd 2019), ed. Patrick Sahle (Frankfurt am Main, 2019), 103 - 106.

${ }^{8}$ Geert Brône and Bert Oben, Eye-Tracking in Interaction: Studies on the Role of Eye Gaze in Dialogue (Amsterdam: John Benjamins, 2018).

${ }^{9}$ Alexander Dunst, Jochen Laubrock, and Janina Wildfeuer, Empirical Comics Research: Digital, Multimodal, and Cognitive Methods (London: Routledge, 2018).
} 
ing with retellings ${ }^{10}$ and film adaptations ${ }^{11}$ to gauge more safely which words are imagined as spoken by what character (and to what music). ${ }^{12}$ The powers of machine learning can be harnessed more productively through learning from transfer and actual reception.

Hence, I am under the impression that a purely text-based, bottom-up approach will not suffice to reach the declared goal of prediction. Narratology has already taken advantage of ongoing research in the fields of multimodality and paralinguistics. Also annotation schemata should go beyond purely text-intrinsic formalism and accommodate for drawing on the ways in which users process and interact with complex narratives. ${ }^{13}$ This may involve annotating for semantic properties in tandem with strictly formal properties. This is a dilemma faced by all of those seeking to reconcile with cultural analytics. High-profile advances in the study of large amounts of narrative text, however, have been achieved without any reference to narratology or to (at least a customary understanding of) narrative aspects of the texts at hand ( e.g. authorship attribution in the cases of J.K. Rowling and Elena Ferrante). These experiments do away with the nitty-gritty of conventional narratological analysis at the advantage of ruthless, yet highly principled reductions of complexity in order to make hidden patterns visible. At the same time, it should be clear that narratology's toolkit has a lot in store to bring to the table of cultural analytics. Annotating for narrative structures of reported speech and variations in ontological modalities may help to reveal that apparently unstructured text is far more structured and/or narrative than has often been taken for granted. Narratologists should also be aware that a mere transposition of these tried-and-trusted methods onto large amounts of unlabelled data necessitates compromise and conceptual tweaking. Hence, this annotation guideline is a productive invitation to a much-needed continuation of the dialogue between narratology and Digital Humanities.

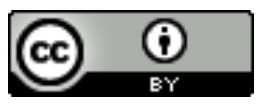

\footnotetext{
${ }^{10}$ Fritz Breithaupt et al., "Fact vs. Affect in the Telephone Game: All Levels of Surprise Are Retold With High Accuracy, Even Independently of Facts," Frontiers in Psychology 9 (November 20, 2018).

${ }^{11}$ Katalin Bálint and András Bálint Kovács, "Focalization, Attachment, and Film Viewers' Responses to Film Characters: Experimental Design with Qualitative Data Collection.," in Making Sense of Cinema: Empirical Studies into Film Spectators and Spectatorship, ed. CarrieLynn D. Reinhard and Christopher J. Olson (Bloomsbury Publishing USA, 2016), 187-210.

${ }^{12}$ Joakim Tillman, "Solo Instruments and Internal Focalization in Dario Marianelli's Pride \& Prejudice and Atonement," in Contemporary Film Music: Investigating Cinema Narratives and Composition, ed. Lindsay Coleman and Joakim Tillman (London: Palgrave Macmillan UK, 2017), 155-86.

${ }^{13}$ Susanna Salem, Thomas Weskott, and Anke Holler, "On the Processing of Free Indirect Discourse," Linguistic Foundations of Narration in Spoken and Sign Languages 247 (2018): 143.
} 
Unless otherwise specified, all work in this journal is licensed under a Creative Commons Attribution 4.0 International License. 